\title{
Consumo de nutrientes, comportamento ingestivo e desempenho de ovinos alimentados com fenos de gramíneas tropicais em diferentes intervalos entre cortes
}

\author{
[Nutrient intake, feeding behavior and performance of sheep fed hay of tropical grasses \\ at different cutting intervals] \\ G.F. Pereira ${ }^{1}$, P.O. Lima $^{2}$, L.C.S.L.C. Assis ${ }^{2}$, J.V. Emerenciano Neto ${ }^{3}$ \\ ${ }^{1}$ Instituto Federal de Educação, Ciência e Tecnologia do Rio Grande do Norte - Apodi, RN \\ ${ }^{2}$ Universidade Federal Rural do Semiárido - Mossoró, RN \\ ${ }^{3}$ Universidade Federal do Vale do São Francisco - Petrolina, PE \\ RESUMO
}

\begin{abstract}
Objetivou-se avaliar o efeito dos fenos de andropogon, buffel e massai em diferentes intervalos de cortes sob consumo, comportamento ingestivo e o desempenho de ovinos. O delineamento experimental foi inteiramente ao acaso. Os tratamentos foram arranjados em fatorial $3 \times 4$ (andropogon, buffel e massai $\mathrm{x}$ intervalos entre corte de 21, 35, 49 e 63 dias). A interação entre as gramíneas e os intervalos não foi significativa para nenhuma das variáveis estudadas. Os maiores consumos de matéria seca, proteína bruta, fibra em detergente neutro e lignina ocorreram com uso do feno de massai, 3,62; 0,48; 2,03 e 0,22\% do peso vivo, respectivamente. Aos 63 dias de intervalo, foram observados os maiores consumos de lignina e os menores de proteína bruta, 0,20 e $0,42 \%$, respectivamente. O menor ganho médio diário (121,1g/dia) e o menor peso final $(17,6 \mathrm{~kg})$ foram dos animais alimentados com buffel. Não houve diferença para o tempo de alimentação e o ócio, com tempo médio despendido de 4,5 e 11,7h/dia, respectivamente. Os fenos de massai e andropogon promovem maior consumo de matéria seca e maior desempenho de ovinos em confinamento, enquanto o intervalo entre corte até 63 dias não modifica essas respostas.
\end{abstract}

Palavras-chave: alimentação animal, cordeiro, forragem, ruminação, semiárido

\begin{abstract}
The objective of this study was to evaluate the effect of Andropogon, Buffel and Massai on different intervals cuts of intake, ingestion behavior and sheep performance. The experimental design was completely randomized. The treatments were arranged in $3 \times 4$ factorial (Andropogon, Buffel and Massai $x$ cut intervals of 21, 35, 49 and 63 days). The interaction between the grasses and the intervals was not significant for any of the studied variables. The highest intakes of dry matter, crude protein, neutral detergent fiber, acid detergent fiber and lignin were for Massai hay, 3.62; 0.48; 2.03 and 0.22\% of the live weight, respectively. At 63 days interval, the highest consumption of lignin and lowest crude protein, 0.20 and $0.42 \%$, respectively, were observed. The lowest daily gain (121.1 g/day) and final weight gain $(17,6 \mathrm{~kg})$ were of Buffel fed animals. There was no difference in feeding time and time, with mean time removed from 4.5 and 11.7h day ${ }^{-1}$, respectively. Hays of Massai and Andropogon promote greater dry matter intake and performance of sheep in confinement, while the cut intervals up to 63 days does not modify these responses.
\end{abstract}

Keywords: animal feed, lamb, forage, rumination, semiarid

\section{INTRODUÇÃO}

A criação de caprinos e ovinos no semiárido brasileiro é uma importante atividade para a subsistência e a fixação do homem no campo. A irregularidade pluviométrica tem causado perdas nesses rebanhos, e uma das alternativas mais viáveis para o fornecimento de volumosos de qualidade é o feno, dadas as facilidades nos processos de produção e armazenamento, bem como o seu valor nutricional (Batista e Souza, 2015).

Recebido em 31 de janeiro de 2017

Aceito em 5 de agosto de 2017

E-mail: genildo.pereira@ifrn.edu.br 
Dentre as gramíneas disponíveis no Brasil para formação de pastagens, os capins andropogon (Andropogon gayanus Kunth), buffel (Cenchrus ciliaris cv. Grass) e massai (Panicum maximum cv. Massai) destacam-se pela tolerância a condições de estresse hídrico (Cavalcante et al., 2016; Luna et al., 2014), característica de regiões semiáridas. Embora a produção de forragem durante o período seco seja nula, a tolerância atribuída a essas gramíneas permite que o excedente forrageiro no período chuvoso seja conservado e utilizado no período seco, sem que haja a necessidade de replantio do pasto a cada ano.

No manejo das pastagens, a definição do intervalo entre cortes é um fator de grande importância, pois modifica tanto a produção quanto a qualidade de forragens. Menores intervalos resultam em menores produções de matéria seca, porém proporcionam valor nutritivo mais elevado (Garcez et al., 2016).

O consumo de alimento e o comportamento ingestivo são aspectos fundamentais na nutrição animal, uma vez que estabelecem a ingestão de nutrientes e, portanto, determinam a resposta do animal (Freitas et al., 2008). Um dos limitadores do consumo é o teor de fibra da dieta. Segundo Cardoso et al. (2006), o aumento do nível de fibra da dieta de cordeiros confinados provoca redução do ganho de peso e redução na eficiência de conversão alimentar, elevando o número de dias para terminar o animal. Por outro lado, o elevado nível de concentrado na dieta de cordeiros também diminui o consumo (Carvalho et al., 2014), além de aumentar o custo por quilograma de carne produzida.

Portanto, objetivou-se avaliar o efeito dos fenos de andropogon, buffel e massai em diferentes intervalos entre cortes sob consumo de nutrientes, o comportamento ingestivo e o desempenho de ovinos em confinamento.

\section{MATERIAL E MÉTODOS}

O experimento foi desenvolvido na fazenda do Instituto Federal de Educação, Ciência e Tecnologia do Rio Grande do Norte, campus Apodi, município de Apodi. O local tem coordenada geográfica de: latitude $5^{\circ} 37^{\prime} 38^{\prime \prime}$ sul e longitude: $37^{\circ} 49^{\prime} 55^{\prime \prime}$ oeste e altitude de $150 \mathrm{~m}$. O clima da região é BSh'W, segundo a classificação de Köppen (Nimer, 1989). As médias das temperaturas mínima e máxima no período experimental foram de 21,29 e $36,81^{\circ} \mathrm{C}$, respectivamente.

Os tratamentos avaliados foram a combinação de três forrageiras sob forma de feno: andropogon (Andropogon gayanus Kunth, cv. Planaltina), buffel (Cenchrus ciliaris cv. Grass) e massai (Panicum maximum cv. Massai), com os intervalos de 21, 35, 49 e 63 dias entre cortes, em arranjo fatorial $3 \times 4$. A forragem colhida das parcelas foi colocada em área calçada e exposta ao sol durante 24 horas para a obtenção dos fenos. Estes foram armazenados em sacos de ráfia, em galpão coberto, até o início do experimento, quando foram triturados em forrageira do tipo desintegrador de grãos, sem peneiras, a fim de diminuir as perdas.

Foram utilizados 36 ovinos machos mestiços da raça Santa Inês, sendo distribuídos três animais para cada combinação fatorial $3 \times 4$. O peso vivo médio inicial dos animais foi de $14,4 \pm 1,9 \mathrm{~kg}$. Estes foram mantidos em regime de confinamento em galpão coberto, em baias individuais, providas de comedouro e bebedouro. Todos os animais receberam vermífugo oral no início do experimento, o qual apresentou duração de 51 dias. O projeto foi submetido ao Ceua (Comitê de Ética no Uso de Animais) da Universidade Federal Rural do Semiárido, tendo recebido parecer (34/2014) favorável.

As dietas foram compostas de 200 gramas de concentrado (68\% milho em grão, $30 \%$ farelo de soja, $2 \%$ mistura mineral) por animal, além do feno (Tab. 1), quantificado para uma sobra de $20 \%$, garantindo, assim, que não ocorresse restrição de alimentos. $\mathrm{O}$ arraçoamento foi realizado duas vezes ao dia, às sete e às 15 horas. Os alimentos foram ofertados separadamente, e não houve sobra de concentrado. As sobras de feno foram pesadas pela manhã e à tarde, retirando-se amostras de $30 \%$, que foram acondicionadas em sacos plásticos, com as devidas identificações referentes aos seus tratamentos. Ao final do experimento, essas amostras foram homogeneizadas e delas foi retirada uma amostra composta para cada tratamento de, aproximadamente, 250 gramas. As amostras dos fenos ofertados, das sobras e do concentrado foram analisadas para determinação da matéria seca (MS), matéria mineral (MM), 
proteína bruta $(\mathrm{PB})$, fibra em detergente neutro (FDN), fibra em detergente ácido (FDA), lignina e extrato etéreo (EE), de acordo com Detmann et al. (2012). O consumo dos nutrientes foi estimado por meio da diferença entre o total do nutriente contido nos alimentos ofertados e o total do nutriente contido nas sobras.

Tabela 1. Composição química centesimal da oferta do concentrado e dos fenos dos capins andropogon, buffel e massai

\begin{tabular}{cccccccc}
\hline Alimento & MS & MM & PB & FDN & FDA & LIG & EE \\
\hline Concentrado & 89,6 & 6,1 & 22,9 & 25,6 & 4,1 & 0,2 & 3,6 \\
Feno de andropogon & 92,3 & 6,6 & 8,6 & 69,3 & 34,3 & 6,4 & 1,2 \\
Feno de buffel & 92,3 & 7,6 & 8,8 & 68,1 & 34,6 & 8,8 & 2,9 \\
Feno de massai & 92,7 & 8,5 & 6,9 & 71,3 & 37,0 & 10,8 & 2,7 \\
\hline
\end{tabular}

MS (matéria seca), MM (matéria mineral), PB (proteína bruta), FDN (fibra em detergente neutro), FDA (fibra em detergente ácido), LIG (lignina) e EE (extrato etéreo).

O ganho de peso diário foi obtido pela diferença entre o peso final e o peso inicial do período experimental dividida pela duração do experimento. A conversão alimentar foi obtida por meio da divisão do consumo de matéria seca total pelo ganho de peso no período experimental.

O comportamento ingestivo dos animais foi observado uma vez por semana, durante três semanas. Para tanto, foi registrado o tempo gasto para ingestão de alimentos, ruminação, ócio e ingestão de água, durante 24 horas/dia, para cada dia de observação, de acordo com Johnson e Combs (1991). As observações visuais dos animais foram realizadas a cada cinco minutos, feitas por três observadores treinados, a cada turno de oito horas, posicionados, estrategicamente, de forma a não interferirem no comportamento natural dos animais. A eficiência de alimentação e ruminação (g MS/h e g FDN/h) foi obtida pela divisão do consumo médio diário de MS e FDN pelo tempo total despendido em alimentação e/ou ruminação em 24 horas, respectivamente (Burger et al., 2000).

O delineamento utilizado foi inteiramente ao acaso, com os tratamentos em arranjo fatorial $3 \times 4$ (três capins x quatro intervalos entre cortes). Os dados foram submetidos à análise de variância e, quando significativos, pelo teste $\mathrm{F}$ $(\alpha=0,05)$; as médias e/ou interações foram comparadas pelo teste de Tukey, para os capins, e pela análise de regressão, para os intervalos. Foi utilizado o seguinte modelo: Yijk: $\mu+\mathrm{Ci}+$ $\mathrm{Tj}+\left(\mathrm{C}^{*} \mathrm{~T}\right) \mathrm{ij}+\alpha \mathrm{ijk}$, em que: Yijk= observação do capim i no intervalo $\mathrm{j}$, repetição $\mathrm{k} ; \mu=$ efeito médio geral; $\mathrm{Ci}=$ efeito do capim $\mathrm{i}, \mathrm{i}=$ andropogon, buffel e massai; $\mathrm{T} j=$ efeito do intervalo entre corte $j, j=21,35,49$ e 63 dias; $\left(C^{*} \mathrm{~T}\right) \mathrm{ij}=$ efeito da interação entre o capim i e o intervalo j; aijk: erro aleatório associado a cada observação ijk.

\section{RESULTADOS E DISCUSSÃO}

A interação entre as forrageiras e os intervalos entre os corte não foi significativa $(\mathrm{P}>0,05)$ para nenhuma das variáveis testadas. Os consumos absolutos de matéria seca ( $\mathrm{g} / \mathrm{dia})$ pelos animais que receberam feno de andropogon e massai não diferiram e foram maiores que os de buffel (Tab. 2). Porém, quando avaliado o consumo por peso metabólico $\left(\mathrm{g} / \mathrm{kg}^{0,75}\right)$ e em relação ao peso vivo (\%PV), os consumos dos três capins foram diferentes entre si.

O maior consumo de matéria seca (CMS, \%PV) foi observado quando utilizado o feno de massai, seguido do andropogon e, por último, do buffel. $\mathrm{O}$ menor consumo de feno de buffel pode ser atribuído à presença das inflorescências, enquanto o maior consumo do feno de massai é explicado pela maior relação folha/colmo desta forrageira. Cabral et al. (2008) encontraram valores de CMS de $0,81 \mathrm{~kg} / \mathrm{dia}$ ou $4,04 \%$ de PV e ganho de peso médio diário de $150 \mathrm{~g} / \mathrm{dia}$, para animais de $20 \mathrm{~kg}$. Os valores observados para os CMS (kg/dia) dos fenos de andropogon, buffel e massai foram de 69,4; 72,8 e 79,1\% do consumo descrito pelos autores, respectivamente. Essa diferença pode ser atribuída à grande diversidade de animais utilizados pelos autores para estimar as equações de consumo. 


\section{Pereira et al.}

Tabela 2. Consumo dos componentes nutricionais e de água por ovinos em confinamento alimentados com fenos de gramíneas tropicais

\begin{tabular}{ccccc}
\hline Compostos nutritivos & Andropogon & Buffel & Massai & CV $(\%)$ \\
\hline Matéria seca (g/dia) & $557,05 \mathrm{a}$ & $399,16 \mathrm{~b}$ & $606,00 \mathrm{a}$ & 15,1 \\
$(\mathrm{~g} / \mathrm{kg} 0,75)$ & $65,0 \mathrm{~b}$ & $50,1 \mathrm{c}$ & $73,2 \mathrm{a}$ & 8,2 \\
$(\% \mathrm{PV})$ & $3,18 \mathrm{~b}$ & $2,51 \mathrm{c}$ & $3,62 \mathrm{a}$ & 7,3 \\
Relação volumoso:concentrado & $1,8 \mathrm{a}$ & $1,0 \mathrm{~b}$ & $2,0 \mathrm{a}$ & 24,6 \\
Matéria mineral (g/dia) & $37,2 \mathrm{~b}$ & $31,7 \mathrm{~b}$ & $45,9 \mathrm{a}$ & 16,6 \\
$(\% \mathrm{PV})$ & $0,21 \mathrm{~b}$ & $0,20 \mathrm{~b}$ & $0,28 \mathrm{a}$ & 8,9 \\
Proteína bruta (g/dia) & $80,0 \mathrm{a}$ & $68,5 \mathrm{~b}$ & $84,4 \mathrm{a}$ & 9,4 \\
(\%PV) & $0,45 \mathrm{~b}$ & $0,38 \mathrm{c}$ & $0,48 \mathrm{a}$ & 6,0 \\
Fibra em detergente neutro (g/dia) & $297,4 \mathrm{a}$ & $187,5 \mathrm{~b}$ & $341,0 \mathrm{a}$ & 19,9 \\
(\%PV) & $1,69 \mathrm{~b}$ & $1,17 \mathrm{c}$ & $2,03 \mathrm{a}$ & 10,8 \\
Fibra em detergente ácido (g/dia) & $127,1 \mathrm{a}$ & $78,0 \mathrm{~b}$ & $145,4 \mathrm{a}$ & 22,9 \\
(\%PV) & $0,72 \mathrm{~b}$ & $0,49 \mathrm{c}$ & $0,87 \mathrm{a}$ & 13,5 \\
Lignina (g/dia) & $28,7 \mathrm{~b}$ & $32,3 \mathrm{~b}$ & $43,5 \mathrm{a}$ & 17,5 \\
(\%PV) & $0,12 \mathrm{c}$ & $0,15 \mathrm{~b}$ & $0,22 \mathrm{a}$ & 16,7 \\
Extrato etéreo (g/dia) & $121,7 \mathrm{c}$ & $150,8 \mathrm{~b}$ & $197,5 \mathrm{a}$ & 10,3 \\
(\%PV) & $0,06 \mathrm{c}$ & $0,08 \mathrm{~b}$ & $0,11 \mathrm{a}$ & 6,7 \\
Água (L/dia) & $1,9 \mathrm{ab}$ & $1,5 \mathrm{~b}$ & $2,0 \mathrm{a}$ & 22,8 \\
\hline
\end{tabular}

Médias seguidas de letras distintas na linha diferem entre si pelo teste de Tukey $(\mathrm{P}<0,05)$.

Quando se compara o CMS predito pelo NRC (Nutrient..., 2007) para ovinos de 20kg e o GMD de $150 \mathrm{~g} / \mathrm{dia}$ (780g/dia ou $3,9 \%$ do PV) aos valores obtidos em g/dia, estes representam 71,4; 58,3 e $77,7 \%$ do valor preconizado pelo NRC para os consumos dos fenos de andropogon, buffel e massai, respectivamente. Porém, o consumo de feno de massai (5\% do PV) se aproximou da estimativa dada pelo NRC, com 92,6\% deste. Segundo Vieira et al. (2013), os modelos propostos por Cabral et al. (2008) e pelo NRC (Nutrient..., 2007) não são eficientes para predizer o CMS por ovinos da raça Santa Inês em confinamento no Brasil. Os autores atribuem isso às diferentes condições edafoclimáticas, de alimentação e das raças dos animais do Nordeste brasileiro.

As relações volumoso/concentrado das dietas ingeridas foram maiores para os fenos de massai $\mathrm{e}$ andropogon $(\mathrm{P}>0,05)$. Isso porque todo $\mathrm{O}$ concentrado ofertado foi consumido, e a variação no consumo se deu em razão da ingestão dos fenos nas dietas. Os consumos de matéria mineral e de lignina foram maiores para animais alimentados com feno de massai $(\mathrm{P}<0,05)$. Tal fato pode ser justificado pelo maior consumo de matéria seca e pelo teor desses componentes na matéria seca desse feno (Tab. 1).

Os consumos de proteína bruta, fibra em detergente neutro e fibra em detergente ácido em g/dia foram semelhantes para os fenos de andropogon e massai e menores para o feno de buffel $(\mathrm{P}<0,05)$ (Tab. 2), enquanto o consumo em $\%$ do peso vivo diferiu entre todos os fenos, com maior consumo no feno de massai e menor no de buffel. O consumo desses componentes se comportou conforme os consumos (g/dia e \% do $\mathrm{PV}$ ) de matéria seca. O consumo de PB (\% do PV) na dieta com feno de massai foi igual ao observado por Mizubuti et al. (2016) para ovinos recebendo deitas com alta relação volumoso:concentrado (70:30), condição semelhante à dessa dieta (63:33). Em todos os tratamentos, o consumo total de proteína bruta foi inferior aos $99 \mathrm{~g} / \mathrm{dia}$ preconizados por Cabral et al. (2008) para ganhos de peso de $150 \mathrm{~g} / \mathrm{dia}$ em ovinos de $20 \mathrm{~kg}$, fato que demonstra um bom potencial de produção dos animais utilizados.

Os consumos de FDN em todos os tratamentos podem ter limitado o consumo de MS e dos demais nutrientes. Segundo Macedo Júnior et al. (2006), a máxima ingestão de forragem por ovelhas Santa Inês ocorre em dietas com 28,0\% de FDN, com consumo de $78,2 \mathrm{~g} / \mathrm{kg}^{0,75}$. Os autores destacam que, em dietas com alto teor de fibra, o consumo será limitado pelo efeito do enchimento provocado pelo alimento. Nesta pesquisa, os consumos de FDN foram de 53,3; 46,7 e $56,3 \%$ da dieta total de MS para os fenos de andropogon, buffel e massai, respectivamente. Os resultados obtidos são satisfatórios, pois, para 
se obterem os resultados dos autores, a participação do volumoso na dieta não poderia passar de $30 \%$.

O consumo de água só diferiu entre os animais alimentados com os fenos de massai e buffel, provavelmente devido ao maior consumo de matéria seca no feno de massai. Todos os consumos de água observados no experimento foram maiores que os relatados por Souza et al. (2010) e pelo NRC (Nutrient..., 2007), que recomenda em torno de 0,800L/animal/dia. Provavelmente, esse maior consumo foi decorrente das altas temperaturas locais e do alto teor de matéria seca da dieta (Tab. 1).
Os consumos de matéria seca, FDN, FDA e EE não diferiram $(\mathrm{P}>0,05)$ em função dos intervalos entre os cortes dos capins (Tab. 3). Esse comportamento também foi observado por Cavalcante et al. (2016), em ovinos alimentados com fenos de andropogon em diferentes idades. Os autores constataram que só havia ocorrido redução no consumo de MS e FDN (\%PV) quando a idade de rebrota passou de 84 para 112 dias. Os autores recomendam que o corte do andropogon para confecção de feno seja entre 56 e 84 dias, assim potencializam-se o consumo voluntário e os teores de digestibilidade.

Tabela 3. Consumo dos componentes nutricionais por ovinos em confinamento alimentados com fenos de gramíneas tropicais em diferentes intervalos entre cortes

\begin{tabular}{|c|c|c|c|c|c|c|}
\hline \multirow{2}{*}{ Compostos nutritivos } & \multicolumn{4}{|c|}{ Intervalo entre corte (dia) } & \multirow{2}{*}{ Equação } & \multirow{2}{*}{$\mathrm{R}^{2}$} \\
\hline & 21 & 35 & 49 & 63 & & \\
\hline Matéria seca (g/dia) & 638,0 & 573,3 & 590,0 & 570,9 & $y=593,0$ & - \\
\hline$(\% \mathrm{PV})$ & 3,10 & 3,08 & 3,15 & 3,10 & $\mathrm{y}=3,11$ & - \\
\hline Matéria mineral (g/dia) & 48,9 & 41,4 & 43,2 & 41,0 & $\mathrm{y}=50,227-0,1571 \mathrm{x}^{*}$ & 60,4 \\
\hline$(\% \mathrm{PV})$ & 0,24 & 0,22 & 0,23 & 0,23 & $y=0,23$ & - \\
\hline Proteína bruta (g/dia) & 90,8 & 76,4 & 73,3 & 70,6 & $y=96,904-0,4559 x^{*}$ & 83,7 \\
\hline$(\% \mathrm{PV})$ & 0,46 & 0,43 & 0,43 & 0,42 & $y=0,4702-0,0008 x^{*}$ & 69,7 \\
\hline Fibra em detergente neutro (g/dia) & 360,8 & 317,4 & 334,1 & 315,0 & $y=331,8$ & - \\
\hline$(\% \mathrm{PV})$ & 1,66 & 1,62 & 1,68 & 1,57 & $y=1,63$ & - \\
\hline Fibra em detergente ácido (g/dia) & 158,5 & 141,5 & 147,6 & 139,7 & $y=146,8$ & - \\
\hline$(\% \mathrm{PV})$ & 0,71 & 0,69 & 0,71 & 0,66 & $y=0,69$ & - \\
\hline Lignina (g/dia) & 29,9 & 33,9 & 34,3 & 41,2 & $y=24,543+0,2446 x^{*}$ & 89,2 \\
\hline$(\% \mathrm{PV})$ & 0,13 & 0,16 & 0,17 & 0,20 & $y=0,0991+0,0016 x^{*}$ & 90,8 \\
\hline Extrato etéreo (g/dia) & 15,8 & 15,1 & 16,7 & 15,0 & $y=15,7$ & - \\
\hline$(\% \mathrm{PV})$ & 0,08 & 0,08 & 0,09 & 0,08 & $y=0,08$ & - \\
\hline
\end{tabular}

* significativo a $5 \%$ de probabilidade.

Os consumos de MM (g/dia), PB (g/dia e \% PV) e lignina (g/dia e \% PV) se ajustaram a equações lineares de regressão, em que se observou que, com o aumento dos intervalos entre os cortes, ocorreu redução no consumo de $\mathrm{MM}$ e $\mathrm{PB}$ e aumento no consumo de FDA. Esse comportamento já era esperado, pois, ao envelhecer, a planta diminui os constituintes do conteúdo celular e aumenta a espessura da parede celular.

Os tempos despendidos com alimentação e ócio não foram afetados pelos capins $(\mathrm{P}>0,05)$, com valores médios de 4,54 e $11,7 \mathrm{~h} / \mathrm{dia}$, respectivamente. $\mathrm{O}$ tempo de ruminação $(\mathrm{P}<0,05)$ diferiu apenas entre os animais alimentados com os fenos de andropogon e buffel. O menor tempo observado para o feno de buffel foi resultado da menor ingestão de MS e de FDN pelos animais. Carvalho et al. (2008) encontraram tempo semelhante entre alimentação, ruminação e ócio em pesquisas com níveis de torta de dendê e cacau em dieta de ovinos. Os autores citam que alterações nos tempos de alimentação e ruminação são comuns em dietas com variação nos teores de fibra, conforme ocorrido nesta pesquisa. 


\section{Pereira et al.}

Tabela 4. Tempo despendido em alimentação, ruminação, ócio, eficiência de alimentação e de ruminação, ganho médio diário, conversão alimentar e peso vivo final de ovinos alimentados com fenos de gramíneas tropicais

\begin{tabular}{lcccc}
\multicolumn{1}{c}{ Atividades } & Andropogon & Buffel & Massai & CV (\%) \\
\hline Alimentação (h/dia) & $4,5 \mathrm{a}$ & $4,4 \mathrm{a}$ & $4,7 \mathrm{a}$ & 21,3 \\
Ruminação (h/dia) & $8,4 \mathrm{a}$ & $7,1 \mathrm{~b}$ & $7,6 \mathrm{ab}$ & 13,6 \\
Ócio (h/dia) & $11,0 \mathrm{a}$ & $12,5 \mathrm{a}$ & $11,7 \mathrm{a}$ & 12,8 \\
Eficiência de alimentação (g MS/h) & $125,76 \mathrm{ab}$ & $98,19 \mathrm{~b}$ & $132,02 \mathrm{a}$ & 25,6 \\
Eficiência de alimentação (g FDN/h) & $67,1 \mathrm{a}$ & $46,5 \mathrm{~b}$ & $74,0 \mathrm{a}$ & 27,9 \\
Eficiência de ruminação (g MS/h) & $66,6 \mathrm{~b}$ & $56,8 \mathrm{~b}$ & $82,0 \mathrm{a}$ & 19,0 \\
Eficiência de ruminação (g FDN/h) & $35,5 \mathrm{~b}$ & $26,7 \mathrm{c}$ & $46,0 \mathrm{a}$ & 22,1 \\
Ganho médio diário (g/dia) & $153,6 \mathrm{a}$ & $121,1 \mathrm{~b}$ & $159,0 \mathrm{a}$ & 18,8 \\
Conversão alimentar (g MS/g ganho) & $3,67 \mathrm{a}$ & $3,37 \mathrm{a}$ & $3,87 \mathrm{a}$ & 16,8 \\
Peso final (kg) & $19,7 \mathrm{a}$ & $17,6 \mathrm{~b}$ & $19,1 \mathrm{a}$ & 11,9 \\
\hline
\end{tabular}

Médias seguidas de letras distintas na linha diferem entre si pelo teste de Tukey a 5\% de probabilidade.

As maiores eficiências de alimentação (EA) foram observadas com os fenos de andropogon e massai $(\mathrm{P}<0,05)$. Esse resultado pode ser atribuído aos maiores consumos de MS e FDN desses fenos. Sá et al. (2014) encontraram eficiências de alimentação $136,5 \mathrm{~g} \mathrm{MS} / \mathrm{h}$ e $37,5 \mathrm{~g}$ FDN/h para ovinos alimentados com dietas contendo 25,5\% de farelo de babaçu. Os resultados da $\mathrm{EA}^{\mathrm{MS}}$ foram próximos aos observados no massai e no andropogon. Isso porque o tempo de alimentação $(4,9 \mathrm{~h})$ e o consumo de matéria seca (675g/dia de MS) descritos pelos autores também foram semelhantes aos observados neste trabalho, enquanto o consumo de FDN (185,6g/dia de FDN) foi muito menor que o obtido para massai e andropogon. No presente caso, a maior eficiência de ruminação pode ser explicada pela relação volumoso:concentrado da dieta de aproximadamente 63:33, enquanto os autores utilizaram 39:61. Com a maior participação de volumoso, ocorreu maior ingestão de FDN e, consequentemente, maior $\mathrm{EA}^{\mathrm{FDN}}$.

$\mathrm{O}$ feno de massai proporcionou a maior eficiência de ruminação (g MS/h e g FDN/h). Essa melhor eficiência pode ser explicada pela alta relação folha/colmo dessa cultivar (Emerenciano Neto et al., 2017), que possibilita maior taxa de passagem. Segundo Sá et al. (2014), o aumento no consumo de FDN pelos animais causa redução na eficiência de ruminação, havendo um aumento da concentração de constituintes da parede celular nas dietas. Embora o menor consumo de FDN tenha sido de feno de buffel (Tab. 2), a maior eficiência de ruminação não foi observada, em razão de o tempo de ruminação não ter diferido do massai (Tab. 3).

O ganho de peso médio diário (GMD) e o peso final dos animais alimentados com os fenos de massai e andropogon não diferiram entre si (Tab. 4), mas foram maiores que dos animais alimentados com feno de buffel $(\mathrm{P}<0,05)$. Esse resultado pode ser atribuído ao maior consumo de matéria seca (Tab. 2) desses animais comparados aos alimentados com buffel. Embora os animais alimentados com massai tenham apresentado maior consumo de PB (\% do PV) e de EE quando comparados aos animais alimentados com andropogon (Tab. 2), os ganhos de peso dos animais não diferiram entre eles por causa do maior consumo de lignina no massai.

Apesar de o consumo de matéria seca observado ter sido menor que o preconizado por Cabral et al. (2008) e pelo NRC, os GMD nos fenos de massai e andropogon foram semelhantes aos $150 \mathrm{~g} /$ dia idealizados pelos autores para dietas de, no mínimo, 30\% de concentrado. Assim, pode-se inferir que a qualidade da dieta (Tab. 1) foi capaz de compensar a menor quantidade ingerida.

A conversão alimentar não diferiu em função dos capins $(\mathrm{P}>0,05)$, com média geral de $3,6 \mathrm{~kg}$ de MS, ingerida para transformar em um $\mathrm{kg}$ de PV. Esse resultado é maior do que o encontrado por Lima et al. (2013), em que foram obtidos valores de 5,4; 6,2 e 6,9 kg de MS/kg de ganho, em dietas para cordeiros Morada Nova, com idade de, aproximadamente, 75 dias e peso vivo de $17,0 \mathrm{~kg}$ ao iniciar o experimento, com alimentação de silagem de ponta de cana, silagem de soja e concentrado. Os altos valores de conversão 
alimentar obtidos só foram possíveis em razão de os animais se encontrarem em fase de alta aceleração do crescimento, entre 70 e 90 dias de idade ao iniciarem o experimento.

O comportamento ingestivo, a eficiência de alimentação, o ganho médio diário e a conversão alimentar não foram afetados pelo intervalo entre os cortes dos capins $(\mathrm{P}>0,05)$. Já a eficiência de ruminação da MS e do FDN se ajustou a modelos de regressão linear em função dos intervalos $\left(\mathrm{ER}^{\mathrm{MS}}=84,335-0,377 \mathrm{x}, \mathrm{R}^{2}=99 \%\right.$ e $\mathrm{ER}^{\mathrm{FDN}}=46,042-0,237 \mathrm{x}, \mathrm{R}^{2}=98 \%$ ), e observouse que, com o aumento do tempo entre os cortes dos capins, houve redução na eficiência de ruminação de 20,7 e 24,3\% para a MS e a FDN, respectivamente. Embora o consumo de FDN não tenha sido modificado pelo intervalo entre os cortes (Tab. 3), o maior consumo de lignina pode explicar a redução na eficiência de ruminação desse material. Segundo Jung e Allen (1995), a lignina se destaca como o principal componente limitador da digestão dos polissacarídeos da parede celular no rúmen. $O$ avanço na idade da planta causa aumento na lignificação do tecido estrutural, que restringe a atuação das enzimas digestivas produzidas pelos microrganismos do rúmen (Garcez et al., 2016).

\section{CONCLUSÕES}

Os fenos de massai e andropogon promovem maior consumo de nutrientes e maior desempenho de ovinos em confinamento. Embora os consumos de proteína bruta e matéria mineral sejam menores quando os pastos são manejados em maiores intervalos entre os cortes no andropogon, buffel e massai, o desempenho animal não é prejudicado.

\section{REFERÊNCIAS}

BATISTA, N.L.; SOUZA, B.B. Caprinovinocultura no semiárido brasileiro fatores limitantes e ações de mitigação. Agropecu. Cient. Semiárid. v.11, p.1-9, 2015.

BURGER, P.J.; PEREIRA, J.C.; QUEIROZ, A.C. et al. Comportamento ingestivo em bezerros holandeses alimentados com dietas contendo diferentes níveis de concentrado. Rev. Bras. Zootec., v.29, p.236-242, 2000.
CABRAL, L.S.; NEVES, E.M.O.; ZERVOUDAKIS, J.T. et al. Estimativas dos requisitos nutricionais de ovinos em condições brasileiras. Rev. Bras. Saúde Prod. Anim., v.9, p.529-542, 2008.

CARDOSO, A.R.; PIRES, C.C.; CARVALHO, S. et al. Consumo de nutrientes e desempenho de cordeiros alimentados com dietas que contêm diferentes níveis de fibra em detergente neutro. Cienc. Rural, v.36, p.215-221, 2006.

CARVALHO, D.M.G.; REVERDITO, R.; CABRAL, L.S. et al. Níveis de concentrado na dieta de ovinos: consumo, digestibilidade e parâmetros ruminais. Semin. Cienc. Agrar., v.35, p.2649-2658, 2014.

CARVALHO, G.G.P.; PIRES, A.J.V.; SILVA, R.R. et al. Comportamento ingestivo de ovinos Santa Inês alimentados com dietas contendo farelo de cacau. Rev. Bras. Zootec., v.37, p.660665, 2008.

CAVALCANTE, A.C.; SALIBA, E.O.S.; GONÇALVES, L.C. et al. Consumo e digestibilidade aparente do feno de Andropogon gayanus colhido em três idades diferentes. Cienc. Anim. Bras., v.17, p.482-490, 2016.

DETMANN, E.; SOUZA, M.A.; VALADARES FILHO, S.C. et al. Métodos para análise de alimentos - INCT - Ciência Animal. Visconde do Rio Branco: Suprema, 2012. 214p.

EMERENCIANO NETO, J.V.; DIFANTE, G.S.; LANA, A.M.Q. et al. Sward structure and herbage accumulation of massai guineagrass pastures managed according to pre-grazing heights, in the northeast of Brazil. J. Agric. Sci., v.9, p.155-163, 2017.

FREITAS, A.W.P.; ROCHA, F.C.; ZONTA, A. et al. Consumo de nutrientes e desempenho de ovinos alimentados com dietas à base de canade-açúcar hidrolisada. Pesqui. Agropecu. Bras. v.43, p.1569-1574, 2008.

GARCEZ, B.S.; ALVES, A.Z.; ARAÚJO, D.L.C. et al. Degradabilidade ruminal do capim colonião (Panicum maximum jacq. cv. colonião) em três idades pós-rebrota. Acta Vet. Brasilica, v.10, p.130-134, 2016. 
JOHNSON，T.R.; COMBS，D.K. Effects of prepartum diet, inert rumen bulk, and dietary polyethylene glycol on dry matter intake of lactating dairy cows. J. Dairy Sci., v.74, p.933944, 1991.

JUNG, H.J.G.; ALLEN, M.S. Characteristics of plant cell wall affecting intake and digestibility of forages by ruminants. J. Anim. Sci., v.73, p.2774-2790, 1995.

LIMA, J.A.; GAVIOLI, I.L.C.; BARBOSA, C.M.P. et al. Soybean silage and sugarcane tops silage on lamb performance. Cienc. Rural, v.43, p.1478-1484, 2013.

LUNA, A.A.; DIFANTE, G.S.; MONTAGNER, D.B. et al. Características morfogênicas e acúmulo de forragem de gramíneas forrageiras, sob corte. Biosci. J., v.30, p.1803-1810, 2014.

MACEDO JUNIOR, G.L.; PÉREZ, J.R.O.; ALMEIDA, T.R.V. et al. Influência de diferentes níveis de fdn dietético no consumo e digestibilidade aparente de ovelhas Santa Inês. Cienc. Agrotec., v.30, p.547-553, 2006.

MIZUBUTI, Y.; SYPERRECK, M.A.; RIBEIRO, E.L.A. et al. Consumo, digestibilidade e balanço de nitrogênio em ovinos alimentados com rações contendo torta de Crambe. Arq. Bras. Med. Vet. Zootec., v.68, p.761-768, 2016.
NIMER, E. Climatologia do Brasil. Rio de Janeiro: IBGE, 1989. 421p.

NUTRIENT requirement of small ruminants: sheep, goats, cervids and new world camelids. Washington: National Academy Press, 2007. $384 \mathrm{p}$.

SÁ, H.C.M.; BORGES, I.; MACEDO JUNIOR, G.L. et al. Consumo e comportamento ingestivo de ovinos alimentados com inclusões crescentes da farinha do endocarpo I do babaçu (Orbignya spp.). Cienc. Rural, v.44, p.2084-2089, 2014.

SOUZA, E.J.O.; GUIM, A.; BATISTA, Â.M.V. et al. Comportamento ingestivo e ingestão de água em caprinos e ovinos alimentados com feno e silagem de maniçoba. Rev. Bras. Saúde Prod. Anim., v.11, p.1056-1067, 2010.

VIEIRA, P.A.S.; PEREIRA, L.G.R.; AZEVEDO, J.A.G. et al. Development of mathematical models to predict dry matter intake in feedlot Santa Ines rams. Small Ruminant Res., v.112, p.78-84, 2013. 